\title{
Prevalence of peripheral and extra-articular disease in ankylosing spondylitis versus non-radiographic axial spondyloarthritis: a meta-analysis
}

Janneke J. de Winter ${ }^{1}$, Leonieke J. van Mens ${ }^{1}$, Désirée van der Heijde ${ }^{2}$, Robert Landewé1 and Dominique L. Baeten ${ }^{1,3^{*}}$

\begin{abstract}
Background: Peripheral disease (arthritis, enthesitis and dactylitis) and extra-articular disease (uveitis, psoriasis and inflammatory bowel disease) is common in ankylosing spondylitis (AS) and non-radiographic axial spondyloarthritis (nr-axSpA). So far, however, summary data on the prevalence are lacking. The objective of this meta-analysis was to assess the prevalence of peripheral and extra-articular manifestations in ankylosing spondylitis (AS) and nr-axSpA.

Methods: We performed a systematic literature search to identify publications describing the prevalence of peripheral and extra-articular disease manifestations in patients with AS and nr-axSpA. We assessed the risk of bias and betweenstudy heterogeneity, and extracted data. Pooled prevalence and prevalence differences were calculated.

Results: Eight studies comprising 2236 patients with AS and 1242 with nr-axSpA were included: 7 of the studies were longitudinal cohort studies. There was male predominance in AS (70.4\%, $95 \% \mathrm{Cl} 64.4,76.0 \%)$ but not in nr-axSpA (46.8\%, $95 \% \mathrm{Cl} 41.7,51.9)$, which was independent of the prevalence of human leukocyte antigen (HLA)-B27. The prevalence of HLA-B27 was similar in AS (78.0\% (95\% Cl 73.9, 81.9\%) and nr-axSpA $(77.4 \%, 95 \% \mathrm{Cl} 68$. 9, $84.9 \%)$ ). The pooled prevalence of arthritis (29.7\% (95\% Cl 22.4, $37.4 \%)$ versus $27.9 \%(95 \% \mathrm{Cl}$ 16.0, $41.6 \%)$ ), enthesitis $(28.8 \%(95 \% \mathrm{Cl} 2.6,64.8)$ versus $35.4 \%(95 \% \mathrm{Cl} 6.1,71.2))$. dactylitis $(6.0 \%(95 \% \mathrm{Cl} 4.7,7.5 \%)$ versus $6.0 \%$ $(95 \% \mathrm{Cl} 1.9,12.0 \%))$, psoriasis $(10.2 \%(95 \% \mathrm{Cl} 7.5,13.2 \%)$ versus $10.9 \%(95 \% \mathrm{Cl}$ 9.1, $13.0 \%)$ ) and inflammatory bowel disease (4.1\% (95\% Cl 2.3, $6.5 \%$ ) versus $6.4 \%(95 \% \mathrm{Cl} 3.6,9.7 \%))$ were similar in AS and nr-axSpA. The pooled prevalence of uveitis was higher in AS (23.0 \% (95\% Cl 19.2, $27.1 \%)$ ) than in nr-axSpA (15.9\% (95\% Cl 11.8, $20.4 \%)$ ).

Conclusion: Peripheral and extra-articular manifestations are equally prevalent in AS and nr-axSpA, except for uveitis, which is slightly more prevalent in AS. These data provide evidence for the largely equal nature of disease manifestations in nr-axSpA and AS.
\end{abstract}

Keywords: Spondyloarthritis, Axial spondyloarthritis, Ankylosing spondylitis, Non-radiographic axial spondyloarthritis, Peripheral manifestations, Extra-articular manifestations, Meta-analysis

Abbreviations: AS, ankylosing spondylitis; ASAS, Assessment of Spondyloarthritis International Society; (Continued on next page)

\footnotetext{
* Correspondence: d.l.baeten@amc.uva.nl

${ }^{1}$ Department of Clinical Immunology and Rheumatology, Amsterdam

Rheumatology and immunology Center, Academic Medical Center/University

of Amsterdam, Meibergdreef 9, 1105, AZ, Amsterdam, The Netherlands

${ }^{3}$ Department of Experimental Immunology, Academic Medical Center/

University of Amsterdam, Amsterdam, The Netherlands

Full list of author information is available at the end of the article
} 


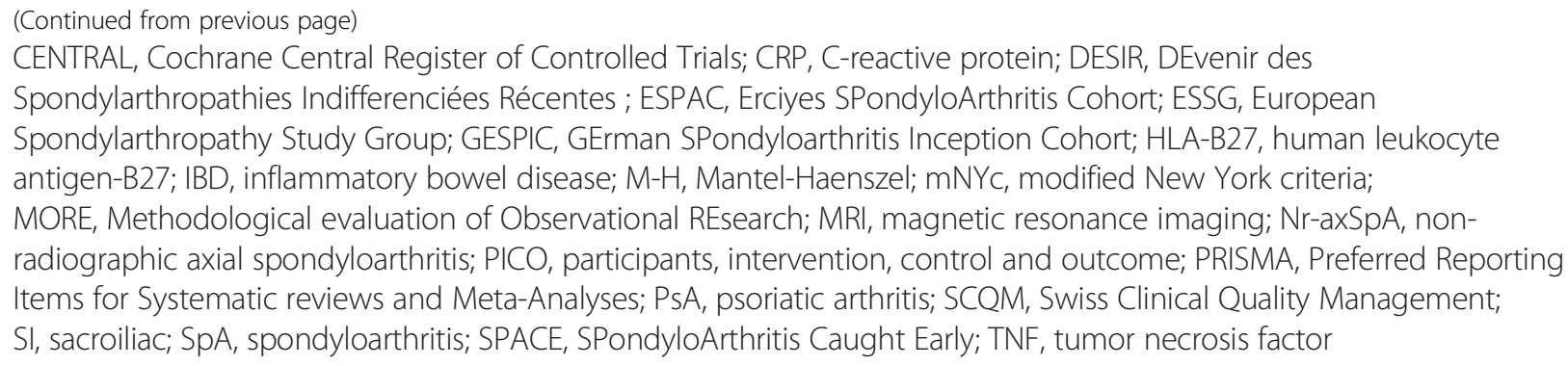

\section{Background}

Spondyloarthritis (SpA) is a prevalent and potentially disabling form of chronic inflammatory arthritis, affecting $0.5-1.5 \%$ of the Western population [1, 2]. SpA has classically been subdivided into several subtypes, including ankylosing spondylitis (AS), psoriatic arthritis (PsA), reactive arthritis, arthritis/spondylitis associated with inflammatory bowel disease (IBD), and undifferentiated SpA. Classification criteria for SpA have been developed by the Assessment of SpondyloArthritis International Society (ASAS), which classifies SpA as axial or peripheral SpA [3-5]. The axial SpA disease spectrum classifies patients as having either ankylosing spondylitis (AS) whether the modified New York criteria (mNYc) are fulfilled, or as having nonradiographic axial SpA (nr-axSpA) in the absence of definite sacroiliac (SI) joint changes on plain radiograph.

Whether nr-axSpA is a different form $[6,7]$ of AS, an early form [8-10] of (AS) or two manifestations in the same disease continuum [11-13] is still subject to debate. There are several reasons to assume that AS and nr-axSpA should be considered as the same disease. First, AS and nr-axSpA in general have similar clinical characteristics, especially when related to disease activity [9-11]. Patients with AS and nr-axSpA not only have similar levels of disease activity, they also have a similar clinical disease course in the absence of tumor necrosis factor (TNF) $\alpha$ inhibiting treatment, as shown by recent longitudinal results from the German Spondyloarthritis Inception Cohort (GESPIC) [14]. Second, patients with nr-axSpA respond similarly to TNFo inhibiting treatment [15-18]. Third, radiographic changes only appear after several years; therefore, the requirement for radiographic change clearly reduces the sensitivity of the mNYc. Not only is sensitivity of the mNYc rather limited, but several studies have shown that scoring of radiographs is subject to considerable inter-reader and intra-reader variability. Scoring by both trained readers and local rheumatologists/ radiologists not only yields modest sensitivity and specificity at best, but also has only moderate agreement in the recognition of radiographic sacroiliitis $[19,20]$. These limitations challenge the crucial role of radiographic scoring in the process of diagnosing AS. Magnetic resonance imaging (MRI) is increasingly being used to visualize inflammation in the SI joints, as active inflammatory lesions are evident on MRI before radiographic lesions are detected [13]. However, MRI also has limitations in terms of scoring agreement, sensitivity, specificity and costs.

On the other hand, AS is characterized by male predominance and a higher level of C-reactive protein (CRP) in comparison to nr-axSpA [9-11]. Other studies suggest that AS and nr-axSpA differ in their genetics, as in some studies human leukocyte antigen (HLA)-B27 carriage is higher in AS than in nr-axSpA [21, 22], whilst other studies suggest there is no difference in HLA-B27 carriage between the two $[9,23,24]$.

Even though spinal inflammation and structural damage are the main features of axial SpA, many patients have concomitant peripheral disease (arthritis, enthesitis, dactylitis) and/or extra-articular disease (uveitis, IBD, psoriasis). In AS, previous studies have reported 18-58 \% prevalence of arthritis [9, 11, 25-27], 34-74 \% prevalence of enthesitis of $[9,25]$ and a $6-8 \%$ prevalence of dactylitis $[9,26,28]$ (reported at any time during the disease course). The reported prevalence of uveitis occurring at some point in time during the course of the disease varies from $22-37 \%[25,27,29-31]$, and the prevalence of IBD is estimated at $4-16 \%[27,30-34]$ and the prevalence of psoriasis at $4-9 \%[6,27,30,31,33,34]$.

In contrast, the prevalence of peripheral and extraarticular disease manifestations in $\mathrm{nr}$-axSpA remains less well-defined. Hypothesizing that AS and nr-axSpA reflect subsets of a single disease entity and have similar disease burden, we performed a meta-analysis of published studies of axial SpA in order to assess if the best available estimate of the prevalence of peripheral and extra-articular disease manifestations is similar in AS and nr-axSpA.

\section{Methods}

We conducted a literature search by database searching, citation searching, "pearl growing" [35] and reference list checking. We performed this systematic review and metaanalysis in accordance with the Preferred Reporting Items for Systematic reviews and Meta-Analyses (PRISMA) guidelines [36]. 


\section{Search methods}

One of the authors (JdW) performed a systematic literature search with the assistance of an experienced librarian (RS). We used the following electronic bibliographical databases: Medline, the Cochrane Central Register of Controlled Trials (CENTRAL) and The Cochrane Library on 1 October 2015 (see Additional file 1: Table S1 for participants, intervention, control and outcome (PICO) and search strategy). The search was performed without language restrictions. In order to retrieve additional references, we used Citation Pearl Growing [35]. Furthermore, primary and secondary references from retrieved publications were manually checked to identify additional studies.

One review author (JdW) screened each title and abstract and selected potentially eligible studies. Thereafter, two review authors (JdW, LvM) independently selected eligible articles according to predetermined selection criteria. If there was any doubt, the full-text article was read by the review authors. Consensus of inclusion was in all cases achieved by discussion. If multiple publications presented data from the same study population, only the publication with the largest sample size was included. Reviews were only included if they presented original data.

\section{Selection criteria for studies}

Studies were included in this meta-analysis if data on prevalence of peripheral and extra-articular disease manifestations in both AS and nr-axSpA were available. We included both longitudinal and cross-sectional studies. Randomized controlled trials and retrospective studies were not included to avoid selection bias and maximize the accuracy of the data. Reporting the prevalence of peripheral and extra-articular disease manifestations did not necessarily have to be the primary outcome of the study.

All patients with axSpA had to fulfill the ASAS axial SpA criteria as defined in 2009 or an equivalent if the study was conducted before 2009 [3] (a modified version of the European Spondylarthropathy Study Group (ESSG) criteria [37]). All patients with AS had to meet the mNY-criteria for AS [38]. All nr-axSpA patients had to fulfill the ASAS MRI criteria or the clinical arm of the ASAS criteria for axial SpA [4] (or an equivalent if the study was conducted before 2009).

\section{SPondyloArthritis Caught Early (SPACE) cohort study}

We added unpublished data to our meta-analysis from one prospective cohort study. The SPACE cohort was described in detail previously [23]. In short, the SPACE cohort is a longitudinal cohort of patients aged 16 years and older, with chronic back pain for at least 3 months but less than 2 years, and with onset before the age of
45 years. In this meta-analysis, we added data for all patients with AS and nr-axSpA included between January 2009 and 2014 at two of the participating centers (Academic Medical Center Amsterdam and the Leiden University Medical Center).

\section{Data extraction and management}

Two review authors (JdW, LvM) independently extracted data using a predesigned form. The following details were extracted whenever available: first author, name of the study, country, year of publication, study design, study characteristics, sample size, mean age of patients, male/ female ratio, mean disease duration, HLA-B27 positivity and percentage of the cohort in which HLA-B27 was measured and the timing and prevalence of peripheral and extra-articular disease manifestations. Whenever data on certain peripheral or extra-articular disease manifestations were missing, we contacted the authors of the article concerned. Furthermore, we requested data on the distribution of male/female participants among HLA-B27-positive and HLA-B27-negative patients with AS and nr-axSpA.

\section{Assessment of risk of bias}

Two review authors (JdW, LvM) assessed the potential risk of bias in all of the included studies by using the Methodological evaluation of Observational REsearch (MORE) checklist [39], which we adapted to our research question. The MORE checklist includes parameters on reporting of statement of potential conflicts of interest, study funding, ethical approval, external validity (was the gold standard for the diagnosis of AS and nr-axSpA used? Was there (reporting on) sampling bias?), and internal validity (how and when was the prevalence of peripheral or extra-articular disease symptoms measured?).

\section{Assessment of heterogeneity}

First, we assessed qualitative heterogeneity across studies by comparing them according to predefined criteria. Second, we evaluated the degree of statistical heterogeneity and inconsistency by using the $T_{2}, \mathrm{Chi}^{2}$ and $I^{2}$ statistics. Heterogeneity was considered significant at $P<0.10$ [40]. $I^{2}$ values of 25,50 and $75 \%$ were considered to indicate low, moderate and high inconsistency, respectively [40]. We used a random effects model for studies that we considered sufficiently homogeneous to include in the meta-analysis, as we anticipated there would not be one true effect size for all studies, despite potential measured quantitative homogeneity [41].

\section{Data synthesis}

We pooled studies in a random-effects model using the Mantel-Haenszel method, which estimates the betweenstudy variation by comparing the result of each study with a Mantel-Haenszel random-effect meta-analysis 
result. Data were calculated as pooled prevalence with the corresponding $95 \%$ confidence interval $(\mathrm{CI})$ and as the difference in pooled prevalence between AS and nr-axSpA, with the corresponding $95 \% \mathrm{CI}$. We performed data analyses using MetaXL [42] in Microsoft Excel 2010 and Review Manager 5. Forest plots were produced for all analyses using Review Manager 5, and we adapted these to our specific needs (to show the difference in prevalence instead of the difference in risk).

\section{Results}

\section{Search}

The electronic database search identified 447 articles (Fig. 1). The use of citation pearl growing resulted in one additional article. After merging for duplicates and screening of the titles and abstracts, we completely reviewed 44 unique articles. One article reported retrospective data. One full-text article could not be retrieved. Five articles did not report symptoms of peripheral or extraarticular disease manifestations. In 25 articles, there was no clear differentiation between AS and nr-axSpA. Two articles did not use the ASAS and mNY criteria to classify axial SpA. Eight articles reported data on duplicate cohort studies. Finally, eight studies were included in the meta-analysis $[6,11,23,43-45]$.

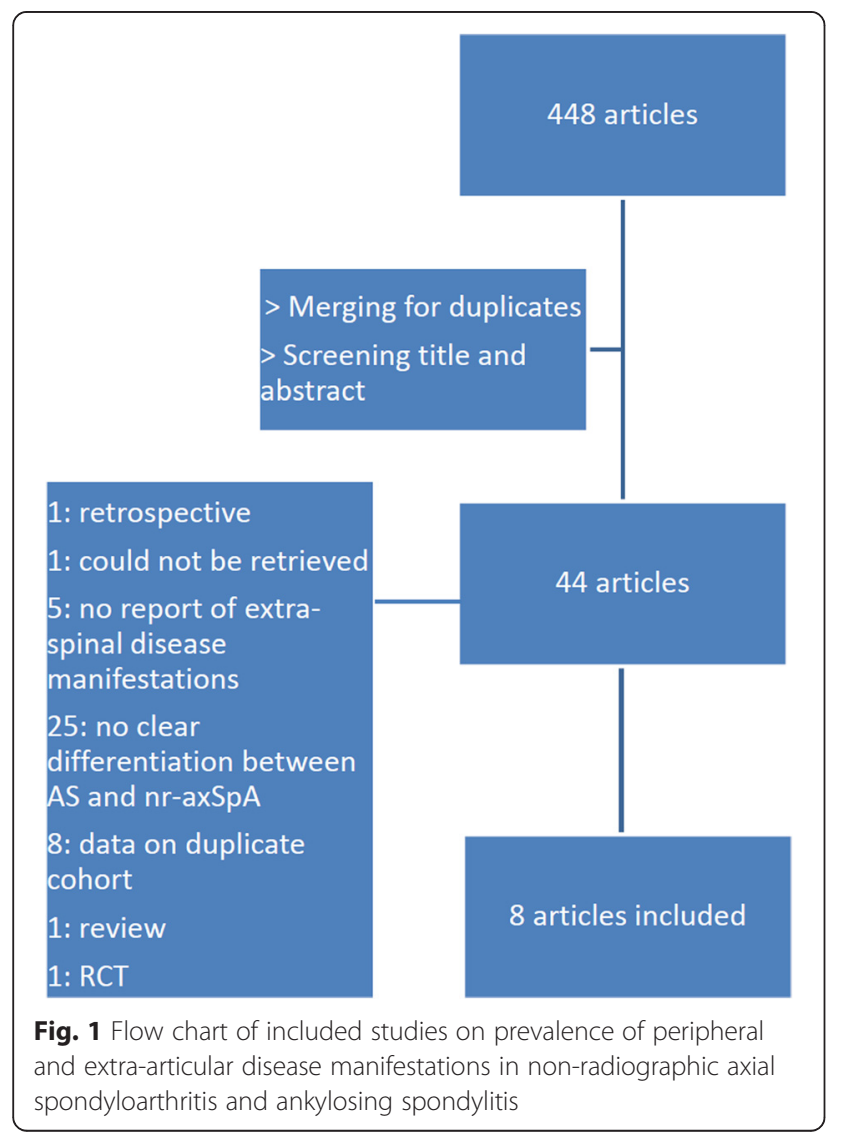

\section{Characteristics of the included studies}

Eight studies fulfilled the inclusion criteria. The characteristics of the enrolled studies are summarized in Table 1. Seven out of eight studies were longitudinal SpA cohort studies. One study was a cross-sectional study of 100 consecutive patients attending outpatient clinics. In total, 3478 patients were included, of whom 2236 had AS and 1242 had nr-axSpA. Patients with AS fulfilled the mNY criteria in all studies. Patients with nr-axSpA fulfilled the ASAS criteria in six out of eight studies. Both GESPIC and Swiss Clinical Quality Management (SCQM) used the ASAS criteria with minor modifications, as patients were included before the development of the ASAS criteria.

The mean symptom duration varied from $1.2 \pm 0.6$ years in AS and $1.0 \pm 0.7$ year in $\mathrm{nr}$-axSpA (Esperanza) to $17.7 \pm 12.3$ years in AS and $12.1 \pm 8.5$ years in $n r-a x S p A$ (Wallis). In pooled analysis the male prevalence of AS was 70.4 \% (CI 64.4-76.0\%) and of nr-axSpA it was $46.8 \%$ (CI 41.7, $51.9 \%$ ), resulting in a difference in pooled prevalence of $23.2 \%$ (CI 15.3, $31.1 \%$ ). When we compared the male prevalence of AS and nr-axSpA among HLA-B27-positive and HLA-B27-negative patients, the difference in prevalence remained $(24.2 \%$ more male patients among patients with AS who were HLA-B27positive (CI 15.1, $32.9 \%$ ) and $22.3 \%$ more male patients among those with AS who were HLA-B27-negative (CI 14.4, $30.0 \%)$ ). The pooled prevalence of HLA-B27 did not differ in AS compared to nr-axSpA, with $78.0 \%$ prevalence in AS (CI 73.9, $81.9 \%$ ) in AS compared to $77.4 \%$ (CI 68.9, $84.9 \%$ ) in nr-axSpA.

All eight studies collected information about peripheral and extra-articular disease manifestations at baseline. Three out of eight studies (GESPIC, Kiltz and SPACE) reported patients who currently had, or had ever had, peripheral and extra-articular manifestations. Three studies only reported disease manifestations that had ever occurred (SCQM, Wallis and ESPAC) and two cohort studies reported only current disease manifestations (DESIR, Esperanza).

\section{Risk of bias}

All published studies (seven out of eight) were published in journals with an impact factor 3.5. The risk of bias summary for all studies is shown in Additional file 2: Table S2. In short, the risk of bias in all studies was considered sufficiently low to be included in this metaanalysis. General bias (role of funding, reporting on ethical approval, conflict of interest) was considered low in all eight studies. Internal validity was considered high in three out of eight studies (Esperanza, SCQM and SPACE) and intermediate in five out of eight studies. The source of the measure of prevalence of peripheral or extra-articular disease manifestations was reported in two of the eight studies (SCQM and SPACE). 
Table 1 Characteristics of the eight included studies

\begin{tabular}{|c|c|c|c|c|c|c|c|c|}
\hline Name cohort or author & $n r-a x S p A n$ & AS $n$ & Study design & Year of inclusion & Data collection & $\begin{array}{l}\text { Maximum disease duration } \\
\text { for inclusion, years }\end{array}$ & $\begin{array}{l}\text { Mean symptom duration } \\
\text { nr-axSpA, mean years (SD) }\end{array}$ & $\begin{array}{l}\text { Mean symptom duration } \\
\mathrm{AS} \text {, mean years (SD) }\end{array}$ \\
\hline GESPIC & 226 & 236 & Cohort & 2000-2004 & Baseline & AS: $<10 ;$ nr-axSpA $<5$ & $2.6(1.7)$ & $5.2(2.3)$ \\
\hline Kiltz & 44 & 56 & Cross-sectional & Unknown & n.a. & No & $9.4(9.5)$ & $12.8(10.7)$ \\
\hline DESIR & 295 & 180 & Cohort & 2007-2010 & Baseline & $<3$ & $1.5(0.9)$ & $1.6(0.9)$ \\
\hline SCQM & 232 & 838 & Cohort & 2005-2011 & Baseline & No & $5.5(1.8-13.7)^{b}$ & $12.7(6.4-22.7)^{b}$ \\
\hline SPACE & 58 & 23 & Cohort & 2009-2014 & Baseline & $<2$ & $1.1(0.6)$ & $1.3(0.7)$ \\
\hline Esperanza & 182 & 109 & Cohort & 2008-2011 & Baseline & $<2$ & $1.0(1.6)$ & $1.2(0.5)$ \\
\hline Wallis & 73 & 639 & Cohort & 2003-2012 & Baseline & No & $12.1(8.5)^{\mathrm{a}}$ & $17.7(12.3)^{\mathrm{a}}$ \\
\hline ESPAC & 132 & 155 & Cohort & 2009-2014 & Unknown & No & $5.8(5.5)$ & $11.7(7.7)$ \\
\hline
\end{tabular}

${ }^{a}$ Mean disease duration. ${ }^{b}$ Median (interquartile range), Nr-axSpA non-radiographic axial spondyloarthritis, AS ankylosing spondylitis, SD standard deviation, GESPIC GErman SPondyloarthritis Inception Cohort, n.a. not applicable, DESIR Devenir des Spondylarthropathies Indifferenciées Récentes, SCQM Swiss Clinical Quality Management, SPACE SPondyloArthritis Caught Early, ESPAC Erciyes SPondyloArthritis 
External validity was considered high in five out of eight studies (Esperanza, Kiltz, SCQM, SPACE and DESIR), intermediate in one out of eight studies (ESPAC) and low in two out of eight studies (GESPIC and Wallis).

\section{Heterogeneity}

When comparing all study characteristics as summarized in Table 1, all eight studies were homogeneous enough to include in the meta-analysis. Statistical heterogeneity was measured for each of the peripheral or extraarticular disease manifestations.

\section{Meta-analysis \\ Peripheral arthritis}

In pooled analysis the prevalence of current peripheral arthritis was $22.9 \%$ (CI 5.7, 46.0 \%) in AS and $25.2 \%$ (CI 8.9, $45.7 \%$ ) in $\mathrm{nr}$-axSpA, resulting in a difference in pooled prevalence of $0.7 \%$ (CI -5.4, $6.7 \%$ ) favoring AS. Quantitative heterogeneity was not statistically significant and the level of inconsistency was moderate $\left(\mathrm{Chi}^{2}=7.29\right.$, $\left.P=0.12, \mathrm{Tau}^{2}=0.00, I^{2}=45 \%\right)$. The pooled prevalence of a history of peripheral arthritis was $29.7 \%$ (CI 22.4, $37.4 \%$ ) in AS and $27.9 \%$ (CI 16.0, $41.6 \%$ ) in nr-axSpA, resulting in a difference in pooled prevalence of $-3.8 \%$ (CI -8.8, $1.1 \%$ ) favoring nr-axSpA (Fig. 2a). Quantitative heterogeneity was not statistically significant and the level of inconsistency was low $\left(\mathrm{Chi}^{2}=1.25, P=0.74\right.$, $\mathrm{Tau}^{2}=$ $\left.0.00, I^{2}=0 \%\right)$.

\section{Enthesitis}

In pooled analysis the prevalence of current enthesitis was $13.6 \%$ (CI 1.8, $31.8 \%$ ) in AS and $19.5 \%$ (CI 7.1, $35.7 \%)$ in nr-axSpA, resulting in a difference in the pooled prevalence of $-4.9 \%$ (CI -10.9, $1.0 \%$ ) favoring nr-axSpA. Quantitative heterogeneity was statistically significant and the level of inconsistency was moderate $\left(\mathrm{Chi}^{2}=11.37, \quad P=0.02, \mathrm{Tau}^{2}=0.00, I^{2}=65 \%\right)$. The pooled prevalence of a history of enthesitis was $28.8 \%$ (CI 2.6, $64.8 \%$ ) in AS and 35.4\% (CI 6.1, 71.2\%) in $\mathrm{nr}$-axSpA, resulting in a difference in pooled prevalence of $-5.4 \%$ (CI -9.7, $0.0 \%$ ) favoring $\mathrm{nr}$-axSpA (Fig. 2b). Quantitative heterogeneity was statistically significant and the level of inconsistency was moderate $\left(\mathrm{Chi}^{2}=12.17, P=0.03, \mathrm{Tau}^{2}=0.00, I^{2}=34 \%\right)$.

\section{Dactylitis}

In pooled analysis the prevalence of current dactylitis was $5.6 \%$ (CI $0.0,16.2 \%$ ) in AS and $5.2 \%$ (CI 0.4, $13.7 \%)$ in $\mathrm{nr}-\mathrm{axSpA}$, resulting in a difference in pooled prevalence of $-0.5 \%$ (CI -2.6-1.6 \%) favoring nr-axSpA. Quantitative heterogeneity was not statistically significant and the level of inconsistency was moderate $\left(\mathrm{Chi}^{2}=3.31\right.$, $\left.P=0.19, \mathrm{Tau}^{2}=0.00, I^{2}=40 \%\right)$. The pooled prevalence of a history of dactylitis was $6.0 \%$ (CI 4.7, $7.5 \%$ ) in AS and $6.0 \%$ (CI 1.9, $12.0 \%)$ in $n r-a x S p A$, resulting in a pooled prevalence difference of $-0.9 \%$ (CI -6.7, $4.8 \%$ ) favoring nr-axSpA (Fig. 2c). Quantitative heterogeneity was statistically significant and the level of inconsistency was moderate $\left(\mathrm{Chi}^{2}=7.37, P=0.03, \mathrm{Tau}^{2}=0.00, I^{2}=\right.$ $73 \%)$.

\section{Uveitis}

In pooled analysis the prevalence of current uveitis prevalence was $5.7 \%$ (CI 1.4-12.2\%) in AS and $6.1 \%$ (CI 2.8-10.5\%) in nr-axSpA, resulting in a difference in pooled prevalence of $-0.3 \%$ (CI -2.3-1.8 \%) favoring nr-axSpA. Quantitative heterogeneity was not statistically significant and the level of inconsistency was low $\left(\mathrm{Chi}^{2}=3.46, P=0.48, \mathrm{Tau}^{2}=0.00, \mathrm{I}^{2}=0 \%\right)$. The pooled prevalence of a history of uveitis was $23.0 \%$ (CI 19.2$27.1 \%$ ) in AS and $15.9 \%$ (CI 11.8-20.4\%) in nr-axSpA, resulting in a difference in pooled prevalence of $6.2 \%(\mathrm{CI}$ 2.7, $9.6 \%$ ) favoring AS (Fig. 3a). Quantitative heterogeneity was statistically significant and the level of inconsistency was low $\left(\mathrm{Chi}^{2}=5.94, P=0.008, \mathrm{Tau}^{2}=0.00\right.$, $\left.I^{2}=16 \%\right)$.

\section{Psoriasis}

In pooled analysis the prevalence of psoriasis was $10.2 \%$ (CI 7.5, -13.2\%) in AS and $10.9 \%$ (CI 9.1, $13.0 \%$ ) in $\mathrm{nr}-\mathrm{axSpA}$, resulting in a difference in pooled prevalence of $-0.7 \%$ (CI $-2.9,-1.6 \%$ ) favoring nr-axSpA (Fig. 3b). Quantitative heterogeneity was not statistically significant and the level of inconsistency was low $\left(\mathrm{Chi}^{2}=7.01, P=\right.$ $\left.0.43, \mathrm{Tau}^{2}=0.00, I^{2}=0 \%\right)$.

\section{Inflammatory bowel disease}

Pooled analysis showed an IBD prevalence of $4.1 \%$ (CI 2.3-6.5 \%) in AS and 6.4\% (CI 3.6-9.7 \%) in nraxSpA, resulting in a pooled prevalence difference of $1.4 \%$ (CI -0.1-2.9 \%) favoring AS (Fig. 3c). Quantitative heterogeneity was not statistically significant and the level of inconsistency was low $\left(\mathrm{Chi}^{2}=6.17, \mathrm{P}=0.52\right.$, $\left.\operatorname{Tau}^{2}=0.00, \mathrm{I}^{2}=0 \%\right)$.

\section{Discussion}

In this meta-analysis we have shown that peripheral disease (arthritis, enthesitis, dactylitis) and extra-articular disease (uveitis, psoriasis, inflammatory bowel disease) manifestations are frequent and, with the exception of a history of uveitis, equally prevalent in AS and nr-axSpA.

Our data on peripheral disease are consistent with earlier published data on peripheral disease in AS, with 18-58 \% prevalence of arthritis [9, 11, 25-27], 34-74 \% prevalence of enthesitis $[9,25]$ and 6-8 \% prevalence of dactylitis $[9,26,28]$ (all reported at any time during the disease). In one study by Vander Cruyssen et al. the 


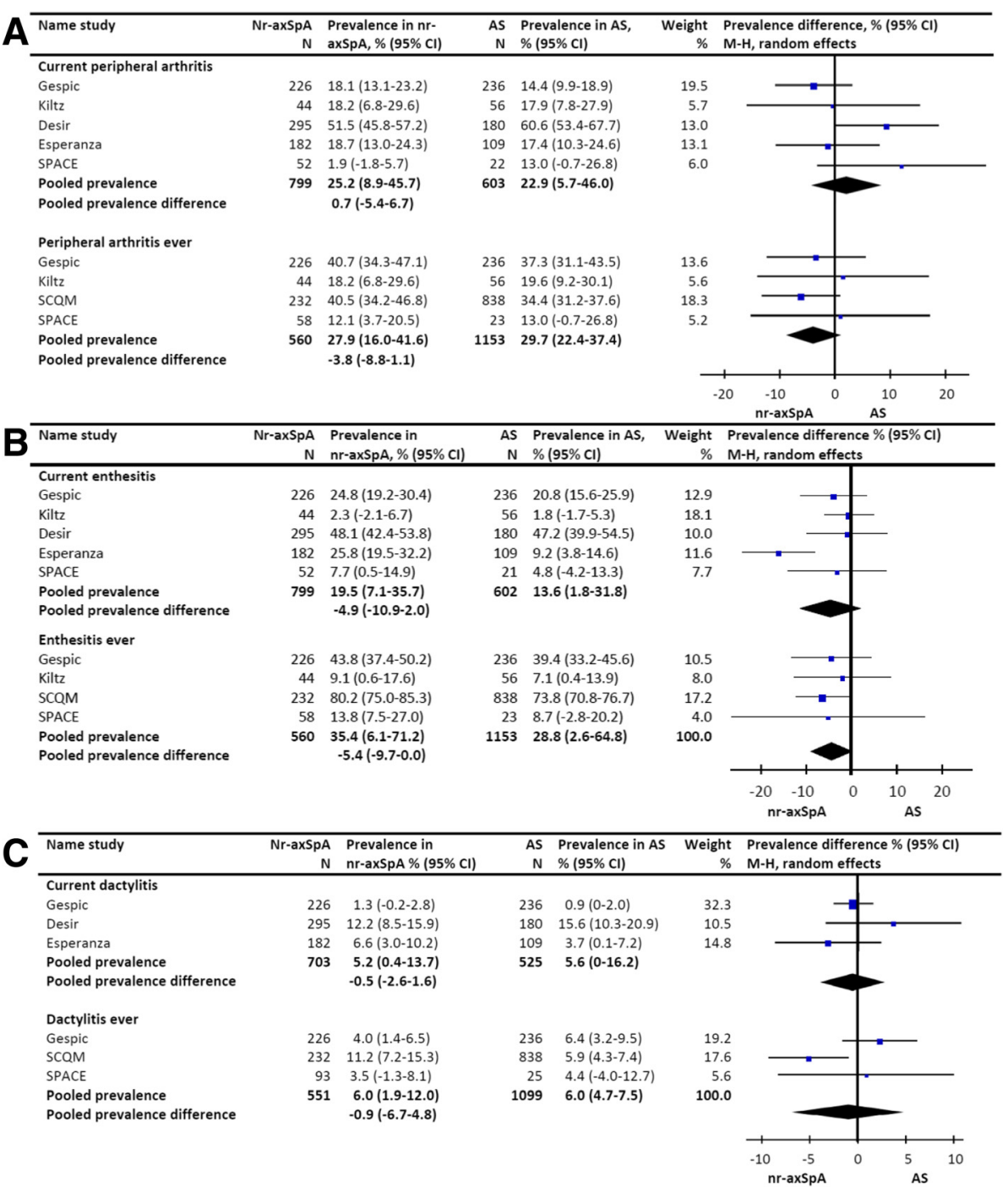

Fig. 2 Prevalence of peripheral manifestations in patients with ankylosing spondylitis and non-radiographic axial spondyloarthritis. a pooled prevalence difference of arthritis in patients with ankylosing spondylitis versus non-radiographic axial SpA. $\mathbf{b}$ pooled prevalence difference of enthesitis in patients with ankylosing spondylitis versus non-radiographic axial SpA. c pooled prevalence difference of dactylitis in patients with ankylosing spondylitis versus non-radiographic axial SpA. GESPIC GErman SPondyloarthritis Inception Cohort, SCQM Swiss Clinical Quality Management, SPACE SPondyloArthritis Caught Early, M-H Mantel-Haenszel

prevalence of arthritis (58 \%) and enthesitis (50\%) (ever occurrence) was higher [25]. Longer mean symptom duration (11 years) and the retrospective reporting in this study may have caused this difference. Importantly, the prevalence of peripheral disease in AS was not reported as the primary outcome in any of the AS studies.

Our prevalence data for extra-articular disease were also in line with previous data on AS, showing 22-37\% prevalence of uveitis $[25,27,29-31], 4-16 \%$ prevalence of IBD [27, 30-34], and 4-9 \% prevalence of psoriasis $[6,27,30,31,33,34]$, which all adds to the robustness of our aggregated estimates. The prevalence of uveitis in our study population was lower than in the metaanalyses of Stolwijk et al. and Zeboulon et al., who reported pooled prevalence of $25.8 \%$ and $32.7 \%$, respectively $[29,30]$. This might be caused by a higher mean disease duration (15.9 years in the meta-analysis of Stolwijk et al. and 17.7 years in the meta-analysis of Zeboulon et al.). Another explanation for this difference in prevalence is that both review studies also included clinical trials, enriched with patients with more active and severe disease.

When we compared patients with AS and nr-axSpA, HLA-B27 was equally prevalent in patients with nr-axSpA and AS. Because HLA-B27 is the main entry requirement for fulfilling the ASAS criteria for nr-axial SpA via the clinical arm, HLA-B27 might be artificially overrepresented in the nr-axSpA arm. However, the Esperanza 


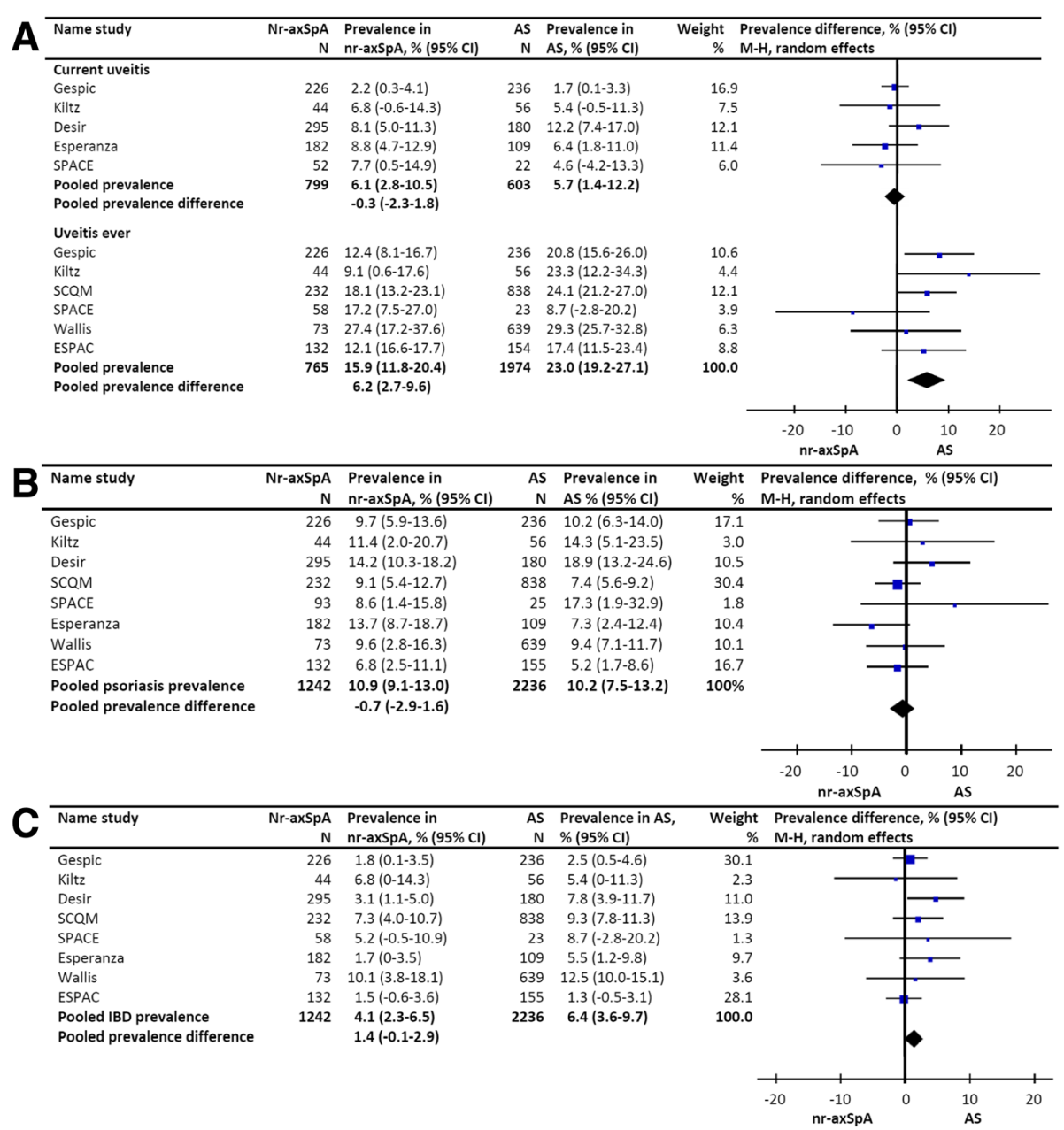

Fig. 3 Prevalence of extra-articular manifestations in patients with ankylosing spondylitis and non-radiographic axial spondyloarthritis. a pooled prevalence difference of uveitis in patients with ankylosing spondylitis versus non-radiographic axial SpA. $\mathbf{b}$ pooled prevalence difference of psoriasis in patients with ankylosing spondylitis versus non-radiographic axial SpA. c pooled prevalence difference of IBD in patients with ankylosing spondylitis versus non-radiographic axial SpA. GESPIC GErman SPondyloarthritis Inception Cohort, SCQM Swiss Clinical Quality Management, SPACE SPondyloArthritis Caught Early, M-H Mantel-Haenszel

cohort differentiated axSpA in AS and nr-axSpA in a clinical and imaging arm, enabling us to compare the HLA-B27 prevalence in both arms. There was no statistically significant difference in the prevalence of HLAB27 in the imaging arm of nr-axSpA (where HLA-B27 is not required to fulfill the ASAS criteria) and in AS (58.3\% vs. $67.6 \%$, respectively) [44], providing evidence for equal HLA-B27 prevalence in nr-axSpA and AS.

Our data show that AS patients were more frequently male than nr-axSpA patients ( $23.2 \%$ difference in prevalence). These results are in line with previous studies showing that male patients with axial SpA have more structural damage on radiographs than female patients [11, 46-48]. Because the $\mathrm{mNY}$ criteria require radiographic evidence of sacroiliitis, channeling of male patients occurs. For nr-axSpA, this channeling does not exist, which is reflected in the equal gender distribution in $\mathrm{nr}-\mathrm{axSpA}$.
Interestingly, when we subcategorized the study population in HLA-B27-positive and HLA-B27-negative patients with AS or nr-axSpA, the male predominance among patients with AS was the same in HLAB27-positive and HLAB27-negative patients, challenging the concept of AS as an HLA-B27-positive driven, predominantly male disease.

Our study data show that peripheral and extra-articular disease manifestations are, with the exception of uveitis, frequent and equally prevalent in $\mathrm{AS}$ and $\mathrm{nr}$-axSpA. These data further support the concept of axial SpA being one disease continuum irrespective of the presence and extent of radiographic changes [11-13]. Two important conclusions can be drawn from this meta-analysis. First, peripheral and extra-articular disease manifestations significantly contribute to the burden of disease in axial SpA. These results are in contrast with the relatively limited 
contribution of peripheral and extra-articular disease to disease monitoring and outcome measurement in axial SpA. Second, these results show that differentiating between AS and nr-axSpA is artificial and should therefore be avoided, especially when selecting patients for research and treatment. These patients can best be combined into one group with axial SpA.

Uveitis is less prevalent in nr-axSpA than in AS (with a difference in the pooled prevalence of $6.2 \%$ ). This difference was not explained by a difference between $\mathrm{nr}$-axSpA and AS in the prevalence of HLA-B27, as this did not differ between the two groups. Zeboulon and colleagues showed that the prevalence of uveitis was higher in HLA-B27-positive patients [29], although this was not confirmed by Stolwijk et al. [30] in their meta-analysis of extra-articular manifestations in AS. The higher prevalence of uveitis in AS in this meta-analysis might be explained by the longer mean disease duration (presuming that uveitis in axial spondyloarthritis does not necessarily occur at the start of the disease and thus needs time to develop). This hypothesis is supported by 1 ) the fact that in the included cohort studies with longer mean disease duration there was generally a higher prevalence of a history of uveitis (Kiltz, SCQM, Wallis): excluding those cohort studies from the meta-analysis resulted in a nonsignificant difference between AS and nr-axSpA in the prevalence of uveitis (data not shown) and 2) the fact that the prevalence of current uveitis did not differ between AS and nr-axSpA.

To our knowledge, this is the first meta-analysis systematically comparing AS with $\mathrm{nr}$-axSpA. Strengths of the current study are the systematic approach in which we have chosen to include only studies that were designed to compare both disease entities, preferably in a prospective manner. Importantly, we have excluded clinical trials that included patients who were selected because of a higher activity and/or severity of their disease (which would have led to channeling bias).

This study has several limitations. First, summarizing the prevalence of peripheral and extra-articular disease manifestations was not the main objective of most of the primary studies included. This might influence the accuracy of reporting these disease manifestations (potential detection bias). Most studies did not report on how the different disease manifestations were measured. We should take into account that the prevalence of some of the disease manifestations that had ever occurred, were mainly obtained by collecting historic patient-reported information (recollection bias). However, the betweenstudy inconsistency of most of the disease manifestations was only moderate (arthritis, enthesitis and dactylitis) or even low (uveitis, psoriasis, IBD), suggesting a significant level of agreement. Second, selection bias is another possible weakness of this meta-analysis and, more importantly, of the included primary studies. We hopefully limited the magnitude of selection bias in this meta-analysis by a thoroughly developed search strategy and other methods to increase finding accuracy (such as citation pearl growing). Within-study selection bias might be caused by different approaches to the inclusion of patients: early spondyloarthritis cohorts (such as DESIR and SPACE) possibly include different patients with shorter disease duration than are included in large observational SpA cohorts.

Furthermore, by applying the ASAS criteria for axial $\mathrm{SpA}$, the prevalence of disease manifestations and characteristics might be artificially raised in $\mathrm{nr}$-axSpA, because they are part of those classification criteria. The higher prevalence of uveitis in patients with AS, however, does not support this hypothesis. On the other hand, the longer mean duration of symptoms in patients with AS when compared to $\mathrm{nr}$-axSpA in five of the eight included studies might confound the interpretation of the results of whether symptoms were ever present, which gives patients with AS more time to accumulate disease manifestations, and might increase the prevalence of manifestations that have ever been present. However, when we left out the studies with substantial differences in symptom duration, the results remained unchanged, except for uveitis, for which the difference no longer remained (data not shown).

\section{Conclusions}

This meta-analysis summarized the prevalence of peripheral or extra-articular disease in patients with AS and $n r-a x S p A$. Awareness of the prevalent nature of these disease manifestations is important in the diagnostic process, both for treatment choices and for health-related quality of life. This meta-analysis provides evidence for the largely equal nature of disease manifestations in $\mathrm{nr}-\mathrm{axSpA}$ and AS, which should have consequences for research and treatment strategies.

\section{Additional files}

Additional file 1: Table S1. PICO and search strategy. (PDF 77 kb)

Additional file 2: Table S2. Estimation of bias. (PDF $91 \mathrm{~kb}$ )

\footnotetext{
Acknowledgements

We acknowledge Sanne Jansen of Lorkeers, MD PhD at the University Medical Center Utrecht, for her assistance with the study design used in the meta-analysis. We acknowledge René Spijker, information retrieval specialist at the Academic Medical Center/University of Amsterdam for assistance with the development of the search strategy. We acknowledge Zineb Ez-Zaitouni, PhD student at the Leiden University Medical Center, for collecting the data for the SPACE cohort. We acknowledge Maxime Dougados and Anna Moltó (DESIR), Martin Rudwaleit (GESPIC), Adrian Ciurea (SCQM), Eva Tomero (Esperanza), Salih Özgöçmen (ESPAC) and Uta Kiltz (Kiltz et al) for providing additional data.
} 


\section{Funding}

DB was supported by a $\mathrm{VICl}$ grant from The Netherlands Organization for Scientific Research (NWO), by an ERC grant and by a grant from the Dutch Arthritis Foundation (Reumafonds).

\section{Availability of data and materials}

Data on the studies included in the meta-analysis are available in the primary articles. Data from the SPACE cohort are not freely available as this is an ongoing cohort.

\section{Authors' contributions}

JdW: study conception and design, acquisition of data, analysis and interpretation of data, drafting the article and final approval of the version of the article to be published. LvM: acquisition of data, analysis and interpretation of data, revising the article and final approval of the version of the article to be published. DvdH: analysis and interpretation of data, revising the article and final approval of the version of the article to be published. RL: study conception and design, analysis and interpretation of data, revising the article and final approval of the version of the article to be published. DB: study conception and design, acquisition of data analysis and interpretation of data, drafting the article, final approval of the version of the article to be published.

\section{Competing interests}

The authors declare that they have no competing interests.

\section{Ethics approval and consent to participate}

All primary studies indicated that ethics approval was given and that included participants gave their informed consent prior to study participation.

\section{Author details}

'Department of Clinical Immunology and Rheumatology, Amsterdam Rheumatology and immunology Center, Academic Medical Center/University of Amsterdam, Meibergdreef 9, 1105, AZ, Amsterdam, The Netherlands. ${ }^{2}$ Department of Rheumatology, Leiden University Medical Center, Leiden, The Netherlands. ${ }^{3}$ Department of Experimental Immunology, Academic Medical Center/University of Amsterdam, Amsterdam, The Netherlands.

\section{Received: 23 March 2016 Accepted: 10 August 2016}

\section{Published online: 01 September 2016}

\section{References}

1. Dougados M, Baeten D. Spondyloarthritis. Lancet. 2011;377:2127-37.

2. Reveille JD, Witter JP, Weisman MH. Prevalence of axial spondylarthritis in the United States: estimates from a cross-sectional survey. Arthritis Care Res (Hoboken). 2012;64:905-10

3. Rudwaleit M, Landewé R, van der Heijde D, Listing J, Brandt J, Braun J, et al. The development of Assessment of SpondyloArthritis international Society classification criteria for axial spondyloarthritis (part I): classification of paper patients by expert opinion including uncertainty appraisal. Ann Rheum Dis. 2009;68:770-6.

4. Rudwaleit $M$, van der Heijde D, Landewé R, Listing J, Akkoc N, Brandt J, et al. The development of Assessment of SpondyloArthritis international Society classification criteria for axial spondyloarthritis (part II): validation and final selection. Ann Rheum Dis. 2009;68:777-83.

5. Rudwaleit $M$, van der Heijde $D$, Landewé $R$, Akkoc N, Brandt J, Chou CT, et al. The Assessment of SpondyloArthritis International Society classification criteria for peripheral spondyloarthritis and for spondyloarthritis in general. Ann Rheum Dis. 2011;70:25-31.

6. Wallis D, Haroon N, Ayearst R, Carty A, Inman RD. Ankylosing spondylitis and nonradiographic axial spondyloarthritis: part of a common spectrum or distinct diseases? J Rheumatol. 2013;40:2038-41.

7. Robinson PC, Wordsworth BP, Reveille JD, Brown M. Axial spondyloarthritis: a new disease entity, not necessarily early ankylosing spondylitis. Ann Rheum Dis. 2013;72:162-4.

8. Huerta-Sil G, Casasola-Vargas JC, Londono JD, Rivas-Ruiz R, Chavez J, Pacheco-Tena $\mathrm{C}$, et al. Low grade radiographic sacroiliitis as prognostic factor in patients with undifferentiated spondyloarthritis fulfilling diagnostic criteria for ankylosing spondylitis throughout follow up. Ann Rheum Dis. 2006;65:642-6

9. Ciurea A, Scherer A, Exer P, Bernhard JJ, Dudler J, Beyeler B, et al. Tumor necrosis factor alpha inhibition in radiographic and nonradiographic axial spondyloarthritis: results from a large observational cohort. Arthritis Rheum. 2013:65:3096-106

10. Kiltz $U$, Baraliakos $X$, Karakostas $P$, Igelmann $M$, Kalthoff $L$, Klink $C$, et al. Do patients with non-radiographic axial spondylarthritis differ from patients with ankylosing spondylitis? Arthritis Care Res (Hoboken). 2012;64:1415-22.

11. Rudwaleit M, Haibel H, Baraliakos X, Listing J, Märker-Hermann E, Zeidler H, et al. The early disease stage in axial spondylarthritis: results from the GErman SPondyloarthritis Inception Cohort. Arthritis Rheum. 2009;60:717-27.

12. Baeten $D$, Breban M, Lories R, Schett G, Sieper J. Are spondylarthritides related but distinct conditions or a single disease with a heterogeneous phenotype? Arthritis Rheum. 2013;65:12-20.

13. Rudwaleit M, Khan MA, Sieper J. Commentary: The challenge of diagnosis and classification in early ankylosing spondylitis: do we need new criteria? Arthritis Rheum. 2005;52:1000-8.

14. Poddubnyy D, Haibel H. Clinical course over two years in patients with early non-radiographic axial spondyloarthritis and ankylosing spondylitis without anti-tumour necrosis factor a treatment: results from the GErman SPondyloarthritis Inception Cohort (GESPIC). Arthritis Rheumatol. 2015:67:2369-75

15. Sieper J, van der Heijde D, Dougados M, Mease PJ, Maksymowych WP, Brown $\mathrm{M}$ a, et al. Efficacy and safety of adalimumab in patients with non-radiographic axial spondyloarthritis: results of a randomised placebo-controlled trial (ABILITY-1). Ann Rheum Dis. 2012;72:815-822.

16. Song I-H, Weiß A, Hermann K-G a, Haibel H, Althoff CE, Poddubnyy D, et al. Similar response rates in patients with ankylosing spondylitis and nonradiographic axial spondyloarthritis after 1 year of treatment with etanercept: results from the ESTHER trial. Ann Rheum Dis. 2013;72:823-5.

17. Callhoff J, Sieper J, Weiß A, Zink A, Listing J. Efficacy of TNFa blockers in patients with ankylosing spondylitis and non-radiographic axial spondyloarthritis: a meta-analysis. Ann Rheum Dis. 2015;74:1241-8.

18. McCormick D, McKnight J, Pendleton a. Anti-TNF response rates in radiographic and non-radiographic axial spondyloarthropathy. Ann Rheum Dis. 2014;74:e21

19. van den Berg R, Lenczner G, Feydy A, van der Heijde D, Reijnierse M, Saraux A et al. Agreement between clinical practice and trained central reading in reading of sacroiliac joints on plain pelvic radiographs: results from the DESIR cohort. Arthritis Rheumatol. 2014;66:2403-11.

20. van Tubergen a, Heuft-Dorenbosch L, Schulpen G, Landewé R, Wijers R, van der Heijde $D$, et al. Radiographic assessment of sacroiliitis by radiologists and rheumatologists: does training improve quality? Ann Rheum Dis. 2003;62:519-25

21. Sieper J, van der Heijde D, Dougados M, Mease PJ, Maksymowych WP, Brown MA, et al. Efficacy and safety of adalimumab in patients with non-radiographic axial spondyloarthritis: results of a randomised placebo-controlled trial (ABILITY-1). Ann Rheum Dis. 2013;72:815-22.

22. Haibel H, Rudwaleit M, Listing J, Heldmann F, Wong RL, Kupper H, et al. Efficacy of adalimumab in the treatment of axial spondylarthritis without radiographically defined sacroiliitis: results of a twelve-week randomized, double-blind, placebo-controlled trial followed by an open-label extension up to week fifty-two. Arthritis Rheum. 2008;58:1981-91.

23. van den Berg $R$, de Hooge M, van Gaalen F, Reijnierse M, Huizinga T, van der Heijde D. Percentage of patients with spondyloarthritis in patients referred because of chronic back pain and performance of classification criteria: experience from the SPondyloArthritis Caught Early (SPACE) cohort. Rheumatology (Oxford). 2013;52:1492-9.

24. Kiltz U, Baraliakos X, Karakostas $P$, Igelmann M, Kalthoff $L$, Klink C, et al. The degree of spinal inflammation is similar in patients with axial spondyloarthritis who report high or low levels of disease activity: a cohort study. Ann Rheum Dis. 2012;71:1207-11.

25. Vander Cruyssen B, Ribbens C, Boonen A, Mielants H, de Vlam K, Lenaerts J, et al. The epidemiology of ankylosing spondylitis and the commencement of anti-TNF therapy in daily rheumatology practice. Ann Rheum Dis. 2007:66:1072-7

26. Paramarta JE, De Rycke L, Ambarus CA, Tak PP, Baeten D. Undifferentiated spondyloarthritis vs ankylosing spondylitis and psoriatic arthritis: a real-life prospective cohort study of clinical presentation and response to treatment. Rheumatology (Oxford). 2013;52:1873-8.

27. Heuft-Dorenbosch $L$, van Tubergen A, Spoorenberg A, Landewé $R$, Dougados M, Mielants $H$, et al. The influence of peripheral arthritis on disease activity in ankylosing spondylitis patients as measured with the Bath Ankylosing Spondylitis Disease Activity Index. Arthritis Rheum. 2004;51:154-9. 
28. Pérez Alamino R, Maldonado Cocco J a, Citera G, Arturi P, Vazquez-Mellado J, Sampaio-Barros PD, et al. Differential features between primary ankylosing spondylitis and spondylitis associated with psoriasis and inflammatory bowel disease. J Rheumatol. 2011;38:1656-60.

29. Zeboulon N, Dougados M, Gossec L. Prevalence and characteristics of uveitis in the spondyloarthropathies: a systematic literature review. Ann Rheum Dis. 2008;67:955-9.

30. Stolwijk C, van Tubergen A, Castillo-Ortiz JD, Boonen A. Prevalence of extraarticular manifestations in patients with ankylosing spondylitis: a systematic review and meta-analysis. Ann Rheum Dis. 2013;74:65-73.

31. Exarchou S, Redlund-Johnell I, Karlsson M, Mellstrom D, Ohlsson C, Turesson C, et al. The prevalence of moderate to severe radiographic sacroiliitis and the correlation with health status in elderly Swedish men-the MrOS study. BMC Musculoskelet Disord. 2013;14:352.

32. Rudwaleit M, Baeten D. Ankylosing spondylitis and bowel disease. Best Pract Res Clin Rheumatol. 2006;20:451-71.

33. Essers I, Ramiro S, Stolwijk C, Blaauw M, Landewé R, van der Heijde D, et al. Characteristics associated with the presence and development of extra-articular manifestations in ankylosing spondylitis: 12-year results from OASIS. Rheumatology (Oxford). 2014;54:633-40.

34. Stolwijk C, Essers I, van Tubergen A, Boonen A, Bazelier MT, De Bruin ML, et al. The epidemiology of extra-articular manifestations in ankylosing spondylitis: a population-based matched cohort study. Ann Rheum Dis. 2014;74:1373-8.

35. Schlosser RW, Wendt O, Bhavnani S, Nail-Chiwetalu B. Use of informationseeking strategies for developing systematic reviews and engaging in evidence-based practice: the application of traditional and comprehensive Pearl Growing. A review. Int J Lang Commun Disord. 2006;41:567-82.

36. Moher D, Liberati A, Tetzlaff J, Altman DG. Preferred Reporting Items for Systematic reviews and Meta-Analyses: the PRISMA statement. J Clin Epidemiol. 2009;62:1006-12.

37. Dougados M, Van der Linden S, Juhlin R, Huitfeldt B, Amor B, Calin A, et al. The European Spondylarthropathy Study Group preliminary criteria for the classification of spondylarthropathy. Arthritis Rheum. 1991;34:1218-27.

38. Van der Linden S, Valkenburg H, Cats A. Evaluation of diagnostic criteria for ankylosing spondylitis. A proposal for modification of the New York criteria. Arthritis Rheumatol. 1984;27:361-8.

39. Shamliyan T a, Kane RL, Ansari MT, Raman G, Berkman ND, Grant M, et al. Development quality criteria to evaluate nontherapeutic studies of incidence, prevalence, or risk factors of chronic diseases: pilot study of new checklists. J Clin Epidemiol. 2011;64:637-57.

40. Higgins JPT, Thompson SG, Deeks JJ, Altman DG. Measuring inconsistency in meta-analyses. BMJ. 2003;327:557-60.

41. Borenstein M, Hedges L, Higgins J, Rothstein H. Introduction to meta-analysis. 2009.

42. Barendregt JJ, Doi S a, Lee YY, Norman RE, Vos T. Meta-analysis of prevalence. J Epidemiol Community Health. 2013;67:974-8.

43. Blachier M, Canouï-Poitrine F, Dougados M, Lethuaut A, Fautrel B, Ferkal S, et al. Factors associated with radiographic lesions in early axial spondyloarthritis. Results from the DESIR cohort. Rheumatology (Oxford). 2013;52:1686-93.

44. Hernández-sanz A, Fernández-carballido VNC, Montilla-morales C, Mulero-mendoza J, de Miguel E. Ankylosing spondylitis and non-radiographic spondyloarthritis: the same syndrome or different diseases? Analyses from Esperanza cohort. In: ACR annual meeting; 2014: Abstract number: 2604.

45. Kilic E, Kilic G, Akgul O, Ozgocmen S. Discriminant validity of the Ankylosing Spondylitis Disease Activity Score (ASDAS) in patients with non-radiographic axial spondyloarthritis and ankylosing spondylitis: a cohort study. Rheumatol Int. 2014;35:981-989.

46. Resnick D, Dwosh IL, Goergen TG, Shapiro RF, Utsinger PD, Wiesner KB, et al. Clinical and radiographic abnormalities in ankylosing spondylitis: a comparison of men and women. Radiology. 1976;119:293-7.

47. Gran JT, Husby G, Hordvik M, Stormer J, Romberg-Andersen O. Radiological changes in men and women with ankylosing spondylitis. Ann Rheum Dis. 1984;43:570-5.

48. Boyer GS, Templin DW, Bowler A, Lawrence RC, Heyse SP, Everett DF, et al. Spondyloarthropathy in the community: differences in severity and disease expression in Alaskan Eskimo men and women. J Rheumatol. 2000;27:170-6.

\section{Submit your next manuscript to BioMed Central and we will help you at every step:}

- We accept pre-submission inquiries

- Our selector tool helps you to find the most relevant journal

- We provide round the clock customer support

- Convenient online submission

- Thorough peer review

- Inclusion in PubMed and all major indexing services

- Maximum visibility for your research

Submit your manuscript at www.biomedcentral.com/submit 